\title{
Lung Surfactant Alterations in Pulmonary Thromboembolism
}

\author{
A. Calkovska ${ }^{1}$, D. Mokra ${ }^{1}$, V. Calkovsky ${ }^{2}$ \\ ${ }^{1}$ Department of Physiology, Jessenius Faculty of Medicine, Comenius University, Martin; ${ }^{2}$ Clinic of Otorhinolaryngology and Head and \\ Neck Injury, Jessenius Faculty of Medicine, Comenius University, Martin and Martin Faculty Hospital, Slovakia
}

\begin{abstract}
Beside neonatal respiratory distress syndrome, secondary surfactant deficiency may occur in patients with mature lungs. Recent studies revealed quantitative and qualitative changes of lung surfactant in pulmonary thromboembolism (PTE) concerning the total phospholipids content in BAL fluid, alterations in surfactant phospholipids classes and a large-to-small aggregates ratio. Reduced expression of surfactant protein A (SP-A) mRNA and SP-A in lung tissue after pulmonary embolism was found. Serum levels of SP-A were significantly higher in patients with PTE than in other lung diseases, except COPD. Surfactant changes in PTE may result from damage of type II cells by hypoxia, leakage of plasma proteins into the airspaces and/or by reactive oxygen species. They can contribute to lung atelectasis and edema, and a further reduction in oxygen saturation as seen in clinical picture of PTE. Surfactant changes are reliable marker of lung injury that might become a prognostic indicator in patients with pulmonary thromboembolism.
\end{abstract}

Key words: pulmonary surfactant; inactivation; thromboembolism; SP-A

\section{INTRODUCTION}

Pulmonary surfactant is a lipoprotein complex that covers the inner surface of the lungs. It prevents collapse of the alveoli and small airways during expiration by reducing surface tension at the air-liquid interface and allows efficient gas exchange at low transpulmonary pressures. It is composed of several phospholipids, neutral lipids and surfactant specific proteins. The largest proportion of phospholipids is phosphatidylcholine, of which dipalmitoylphosphatidylcholine (DPPC) is the major surface-active component. Four native surfactant proteins have been identified. The hydrophobic surfactant proteins B (SP-B) and $\mathrm{C}$ (SP-C) are thought to be important for the surface-tension lowering properties of pulmonary surfactant. Surfactant proteins A (SP-A) and D (SP-D) are hydrophilic and they play a role in surfactant metabolism and in pulmonary host defence [for review, see 1].

Surfactant is produced by alveolar type II cells, where it is stored in intracellular vesicles termed lamellar bodies. After secretion into the alveolar surface it forms tubular myelin and further spreads to a thin film. "Consumed" surfactant is recycled by type II cells or removed by macrophages from alveolar space. Life cycle of natural surfactant is controlled at local, humoral and neural levels [1].

By differential centrifugation two basic forms of pulmonary surfactant were defined - large complexes of active surfactant (large aggregates, LA) and small inferior complexes (small aggregates, SA). A decrease in the large-to-small aggregates ratio is one of the markers of lung injury [2]. This review will focus on changes of pulmonary surfactant system that occur in pulmonary thromboembolism.

\section{HISTORY}

First documented study designed to give an evidence of relationship between pulmonary circulation and surfactant was performed by Finley et al [3]. Occlusion of pulmonary artery in dogs during two hours led to reduction in surfactant activity lasting for six weeks. Sutnick and Soloff [4] examined post mortem surface activity in saline extracts of human lungs involved with emboli. The investigation revealed increased minimal surface tension indicating a severe surfactant abnormality. Incorporation of ${ }^{14} \mathrm{C}$-palmitate into phospholipids by lung slices was also markedly impaired by embolism. These findings support the concept that obstruction to the pulmonary circulation interferes with surfactant production; thus contributing to atelectasis seen in pulmonary embolism. Some years later, bromhexine, known as a stimulator of surfactant synthesis and secretion, had protective effect on the acute impairment of pulmonary function due to microthrombosis in rabbits [5]. Surfactant replacement therapy in two patients with suspect pulmonary embolism was documented in 1991 [6]. Two adolescents (12 and 16 years old) with acute leukemia and severe respiratory failure due to leukemia treatment were given the modified natural surfactant Curosurf. Surfactant administration improved ventilation and oxygenation and made confirmation of the diagnosis possible. All these results probably formed a background for later clinical studies demonstrating a tight relation between surfactant and pulmonary embolism.

\section{Lung SuRfactant in Pulmonary ThromboEMBOLISM}

Surfactant deficiency has been recognized as the cause of respiratory distress syndrome (RDS) in premature 
infants. However, secondary surfactant deficiency resulting from inactivation of surfactant system may occur in patients with mature lungs. Nowadays, there is a growing body of evidence on qualitative and quantitative changes of lung surfactant in pulmonary thromboembolism (PTE) [7]. PTE induced an increase in the total phospholipid content in bronchoalveolar lavage (BAL) fluid on the first day and decrease on the tenth day after the diagnosis of PTE in comparison to control patients without cardiorespiratory disease. Alterations in surfactant phospholipids classes were also observed. On the first day of the disease, relative amounts of phosphatidylcholine (PC) and phosphatidylglycerol (PG) decreased and sphingomyelin (SM), phosphatidylinositol (PI) and lysophosphatidylcholine (Lyso-PC) increased. Concentration of PC, SM and PI did not change significantly in the course of disease.

Another important finding is a change in the surfactant large-to-small aggregates ratio. In patients with PTE, the abundance of large active aggregates (LA) in bronchoalveolar lavage fluid falls in favor of small aggregates (SA) with low surface activity. The rise in SA is supposed to be responsible for an increase in absolute value of phospholipids on the first day of PTE, as this finding correlates with reduction of surfactant biophysical activity in PTE patients [7].

\section{Surfactant-Specific Protein A (SP-A)}

As mentioned above, the protein components constitute approximately $10 \%$ by weight of pulmonary surfactant, half of which consists of four surfactant-associated proteins A, B, C and D. Among them, SP-A is most abundant pulmonary surfactant protein that belongs to the family of innate host defense proteins termed collectins [8]. Beside pulmonary host defense, $\mathrm{SP}-\mathrm{A}$ is also involved in the formation of pulmonary surfactant, as it is essential for the structure of tubular myelin. The levels of SP-A are decreased in the lungs of patients with cystic fibrosis, respiratory distress syndrome, pneumonia and another chronic lung diseases $[8,9]$.

Apart from phospholipids changes, reduced expression of SP-A mRNA and SP-A in lung tissue after pulmonary embolism was found [10]. Reduced SP-A expression in lungs after embolism might be caused by the limited number of SP-A producing type II cells and/or by a reduced SP-A expression of the remaining - uninjured cells - similarly to the lung fibrosis [11].

Interestingly, treatment with low molecular weight heparin (LMWH) was associated with an increased level of lung SP-A in rabbit model of pulmonary embolism [12]. It indicates that the positive effects of LMWH in treatment of pulmonary embolism may be mediated by controlling the surfactant protein metabolism.

Serum SP-A offers a useful clinical marker for interstitial lung diseases (ILD). However, SP-A is occasionally elevated also in non-ILD patients. There was a large study conducted to investigate factors that affect serum SP-A levels in respiratory medicine [13]. A total of 929 patients with respiratory diseases, excluding ILD, pulmonary alveolar proteinosis, pneumonia or adenocarcinoma, were enrolled. Serum SP-A was sig- nificantly higher in current smokers than in never- or ex-smokers, and it was also higher in patients with COPD and pulmonary thromboembolism than in other diseases. In thromboembolism, higher serum levels of SP-A may be explained by increased permeability of alveolar-capillary barrier due to alveolar ischemia, and epithelial and endothelial damage, enabling SP-A to leak into the circulation [13]. It suggests that serum SP-A may represent a useful and valuable marker in diagnostics of pulmonary thromboembolism and assessment of treatment efficiency.

\section{Mechanisms of SuRfactant Alterations}

The degree of surfactant inactivation depends on the extent of pulmonary embolism, and it is supposed to be larger in acute massive forms of PTE accompanied by severe hypoxia and metabolic acidosis. Even though the complex mechanism of pulmonary surfactant injury in PTE is not fully elucidated, several factors may be defined (Fig. 1). An increase in the total phospholipids amount shortly after the onset of PTE can be attributed to enhanced synthesis and/or secretion, perturbation of phospholipids reuptake by alveolar type II cells, or by release of phospholipids from damaged cell membranes. As hyperventilation was shown to have stimulatory effect on surfactant synthesis and secretion [14], another proposed mechanism is a change in breathing pattern which typically occurs in patients with PTE and may promote phospholipids changes. Phospholipid production may be enhanced also by activation of both parts of autonomic nervous system, sympathetic and parasympathetic [15], and by hormonal stimulation.

A late decrease in the total phospholipids in the course of the PTE could reflect type II cell injury as a result of hypoperfusion and hypoxia, or inflammation. Special role is probably played by lysophosphatidylcholine that is generated by phospholipids subjected to phospholipase $\mathrm{A}_{2}$ hydrolysis. Its amount increases soon after PTE and can significantly affect surface tension [7]. Another reason of the decrease in phospholipids content later on may be depletion of intracellular sources of surfactant and/or enhancement of its metabolism [16].

In some patients spontaneous, at least partial, resolution of the thrombus may occur. Reperfusion of the ischemic lung tissue triggers migration of polymorphonuclear cells to alveoli, which results in the increased generation of reactive oxygen species (ROS) [17]. The main source of ROS in the lungs is activated phagocytes that are markedly increased in the BAL fluid in patients with PTE [7]. Concentration of surfactant large aggregates (LA), SP-B, DPPC and PG in the lungs decreases after ischemia/reperfusion [18] and may significantly reduce biological activity of surfactant.

Plasma proteins are important inhibitors of pulmonary surfactant. They reach alveoli in respect of increased permeability of alveolar-capillary membrane. The mechanisms by which plasma proteins inhibit surface adsorption of surfactant molecules are competitive processes: proteins are adsorbed onto the air-liquid interface and occupy space in competition with 


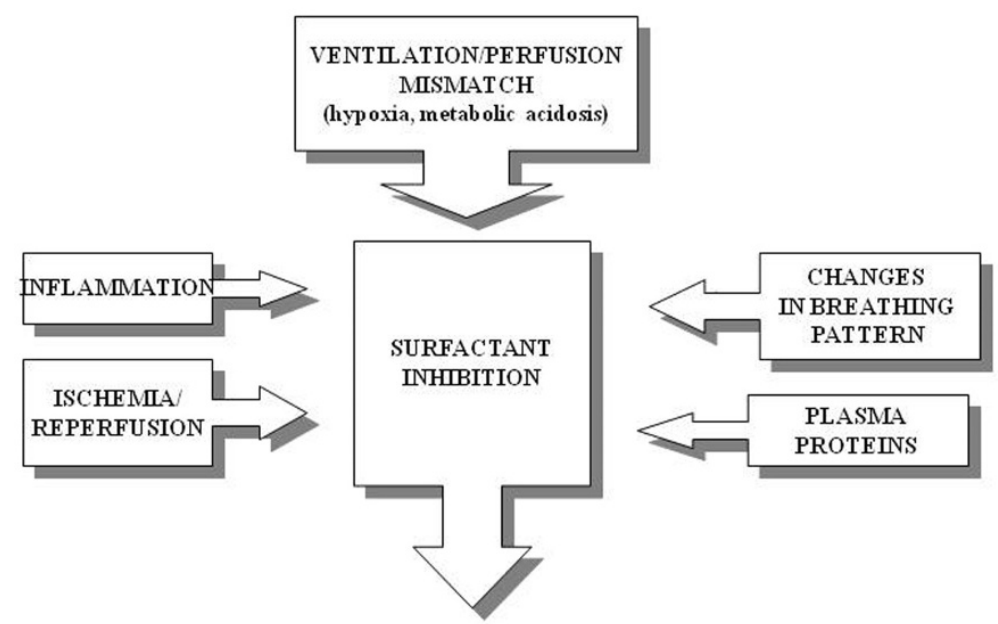

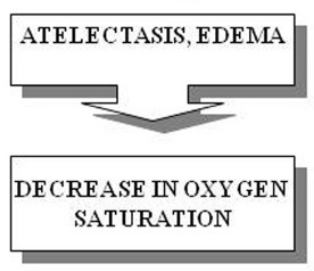

surfactant molecules [19]. Among plasma proteins, albumin has less pronounced inhibitory effects. However, in PTE patients, albumin is probably the most important surfactant inhibitor, as its amount increases in BAL fluid in these patients.

Surfactant injury in patients with PTE may be further intensified by using standard therapeutic methods, mainly artificial pulmonary ventilation at large volumes and high inspiratory pressures. Prolonged mechanical ventilation in patients without acute lung injury is associated with the presence of inflammatory markers and surfactant alterations in BAL fluid [20]. Artificial ventilation, lasting for several days, evoked decreases in total phospholipids, in PC and PG, and in active large surfactant aggregates. Treatment with oxygen may also have negative impact on surfactant system [21].

\section{Pathophysiological CONSEQUENCES}

Disturbance of steady-state condition of the surfactant system by endogenous and exogenous factors is manifested by changes in mechanical properties of the lungs, gas exchange and by reduced lung defense (Fig. 1). Surfactant changes may significantly contribute to the clinical picture of PTE. For instance, atelectasis, developing as a result of ventilation/perfusion mismatch, can be potentiated by qualitative deficiency of pulmonary surfactant, formerly termed as antiatelectatic factor. Moreover, missing antiedematous effects of surfactant result in liquid transudation into the alveoli and lead to lung edema; a relatively common complication of PTE. Both, pulmonary atelectasis and edema lead to further deterioration of blood oxygen saturation.

Patients surviving acute PTE are treated with thromboendarterectomy [22] that in some of these patients may lead to acute lung injury. Probability of lung injury development correlates with levels of parathyroid hormone-related protein (PTHrP). PTHrP
Fig. 1. Mechanisms and pathophysiological consequences of surfactant inactivation in pulmonary thromboembolism.

is an autocrine growth and differentiation factor for alveolar type II epithelial cells producing surfactant. The lower is the PTHrP level in BAL fluid; the higher is the probability of the development acute lung injury [23]. This finding gives another indirect evidence of a relation between surfactant and PTE.

In conclusion, deterioration of gas exchange and lung mechanics in pulmonary embolism are associated with surfactant system alterations. Qualitative and quantitative changes in pulmonary surfactant are a reliable marker of lung injury, and they could be a prognostic indicator in patients with pulmonary thromboembolism.

Acknowledgements: The work was supported by project VEGA No. 1/0061/08 and by the Center of Excellence for Perinatological Research financed by ERDF.

Conflicts of interest: The authors reported no conflicts of interest in relation to this article.

\section{REFERENCES}

[1] Robertson B, van Golde LMG, Batenburg JJ (Eds). Pulmonary surfactant. From molecular biology to clinical practice. Amsterdam - London - New York - Tokyo, Elsevier 1998; $753 \mathrm{pp}$

[2] Gross JN, Kellam M, Young J, Krishnasamy S, Dhand R. Separation of alveolar surfactant into subtypes. A comparison of methods. Am J Respir Crit Care Med 2000; 162: 617-22.

[3] Finley TN, Swenson WE, Clements JA, Gardner RE, Wright RR, Severinghaus JW. Changes in mechanical properties, appearance and surface activity of extracts of one lung following occlusion of its pulmonary artery in the dog. Physiologist 1960; 3(1): 56-61.

[4] Sutnick AI, Soloff LA. Pulmonary arterial occlusion and surfactant production in humans. Ann Intern Med 1967; 67(3): 549-55.

[5] Nowak G, Glusa E, Herbst I, Schreiber S. Effect of bromhexine on microthrombosis in animal experiments. Biomed Biochim Acta 1985; 44(3): 475-84.

[6] Marraro G, Casiraghi G, Riva A. The effects of adminis- 
tering surfactant to two adolescents with leukemia suffering from respiratory distress. Cah Aneshesiol 1991; 39(4): 227-32.

[7] Nakos G, Kitsiouli EI, Lekka ME. Bronchoalveolar lavage alterations in pulmonary embolism. Am J Respir Crit Care Med 1998; 158: 1504-10.

[8] Heinrich S, Hartl D, Griese M. Surfactant protein A from genes to human lung diseases. Curr Med Chem 2006; 13(27): 3239-52.

[9] Gunther A, Siebert C, Schmidt R, Ziegler S, Grimminger F, Yabut M, Temmesfeld B, Walmrath D, Morr H, Seeger W. Surfactant alterations in severe pneumonia, acute respiratory distress syndrome, and cardiogenic lung edema. Am J Respir Crit Care Med 1996; 153: 176-84.

[10] Liu CP, Zhang YJ, Lu WX, Ji YQ, Zhang WH, Wang C. The change of pulmonary surfactant associated protein A in acute pulmonary embolism. Zhonghua Jie $\mathrm{He} \mathrm{He} \mathrm{Hu}$ Xi ZA Zhi 2005; 28(9): 600-3

[11] Goldmann T, Kahler D, Schultz H, Abdullah M, Lang DS, Stellmacher F, Vollmer E. On the significance of surfactant protein A within human lungs. Diagnostic Pathology 2009; 4:8, DOI: 10.1186/1746-1596-4-8.

[12] Liu CP, Lu WX, Liu WG, Chen HW, Wang C. The low molecular weight heparin on rat pulmonary surfactant associated protein A of acute pulmonary embolism. Zhonghua Yi Xue Za Zhi 2007; 87(9): 634-6.

[13] Kobayashi H, Kanoh S, Motoyoshi K. Serum surfactant protein-A, but not surfactant protein-D or KL-6, can predict preclinical lung damage induced by smoking. Biomarkers 2008; 13(4): 385-92.

[14] Power JHT, Barr HA, Jones ME, Nicholas TE: Changes in surfactant pools after a physiological increase in alveolar surfactant. J Appl Physiol 1987; 5: 1902-11.

[15] Oyarzún MJ, Clements JA. Control of lung surfactant by ventilation, adrenergic mediators and prostaglandins in the rabbit. Amer Rev Resp Dis 1978; 117:879-91.

[16] Dietl P, Haller T, Mair N, Frick M. Mechanisms of surfactant exocytosis in alveolar type II cells in vitro and in vivo. News Physiol Sci 2001; 16: 239-43.
[17] Fukahori M, Murata T, Mohammed MU, Fukuyama N, Nakazawa H. Early reperfusion induces alveolar injury in pulmonary embolism. Chest 1997; 111: 198-203.

[18] Markart P, Schmidt R, Ruppert C, Hores C, Silber RE, Borgermann J, Gunther A, Friedrich I. Ischemic and endotoxin pre-conditioning reduce lung reperfusion injuryinduced surfactant alterations. J Heart Lung Transplant 2005; 24(10): 1680-9.

[19] Kobayashi T, Nitta K, Ganzuka M, Inui S. Inactivation of exogenous surfactant by pulmonary edema fluid. Ped Res 1991; 29(4): 353-6.

[20] Tsangaris I, Lekka ME, Kitsiouli E, Constantopoulos S, Nakos G. Bronchoalveolar lavage alterations during prolonged ventilation of patients without acute lung injury. Eur Respir J 2003; 21: 595-601.

[21] Zenri H, Rodriquez-Capote K, McCaig L, Yao LJ, Brackenbury A, Possmayer F, Veldhuizen R, Lewis J. Hyperoxia exposure impairs surfactant function and metabolism. Crit Care Med 2004; 32(5): 1155-60.

[22] Steiner P, Biringer A, Slamen J, Kulisek D, Steinerova M, Mazuch J. Pulmonary embolectomy (report of a successful case). J Cardiovasc Surg (Torino) 1969; 10(1): 67-70.

[23] Hastings RH, Auger WR, Kerr KM, Quintana RA, Deftos LJ. Parathyroid hormone-related protein and lung injury after pulmonary thromboendarterectomy. Regul Pept 2001; 102(1): 1-7.

Address for correspondence:

Prof. Andrea Calkovska

Department of Physiology

Jessenius Faculty of Medicine

Comenius University

Mala Hora 4

SK-03754 Martin

Slovakia

Phone/fax: +421 434131426

Calkovska@jfmed.uniba.sk 